\title{
A atual legislação ambiental e caracterização da área da nascente de Pau Amarelo no município de Garanhuns/PE
}

\author{
The current environmental legislation and characterization of the area of the nascent of Yellow Pau of the municipality \\ Garanhuns / PE
}

\section{Elaynne Mirele Sabino de França', Daniel Dantas Moreira Gomes²}

\author{
' Graduada em Geografia, Pós-Graduanda “Lato Sensu” em Gestão Ambiental, Universidade de Pernambuco, Garanhuns, Brasil. \\ ${ }^{2}$ Graduado em Geografia, Especialista em Geoprocessamento, Mestre em Geologia, Doutorando em Geologia, Universidade Federal do \\ Ceará, Fortaleza, Brasil.
}

\begin{abstract}
Resumo
O presente trabalho realiza um estudo sobre á área que abrange a nascente de Pau amarelo, onde esta localizada no agreste meridional do município de Garanhuns - Pernambuco. Para isso consideramos como arcabouço fundamental os ditames estipulados pela legislação ambiental brasileira presentes: Novo código florestal (Lei, 12.651), CONAMA 303, Plano diretor municipal, para verificar sua atual vigência no contexto ambiental desta área estudada. Podemos constatar a necessidade de atualização, aplicação e fiscalização específica do poder público para a área, pontuando ainda os impactos socioambientais levantados na literatura. Propomos que se possa determinar no diz respeito aos preceitos legislativos que a nascente seja uma área de preservação permanente e promover a conscientização da população em suas ações que estão modificando a qualidade e disponibilidade dos recursos naturais.
\end{abstract}

Palavras-chave: Legislação Ambiental, Garanhuns/PE, Nascente de Pau Amarelo.

\begin{abstract}
This paper conducts a study of the area covering the east of Pau yellow, which is located in the rugged southern municipality of Garanhuns - Pernambuco. To consider it as a fundamental framework dictates set by the Brazilian environmental legislation presents: New Forest Code (Law 12,651), CONAMA 303, Municipal Director Plan to assess their current application in the environmental context of this study area. We can see the need to upgrade, and application specific control of public power to the area, still punctuating the observed environmental impacts. We propose to determine in respect of the regulatory provisions that the source is an area of permanent preservation and awareness in the population that their actions are changing the quality of natural resources.
\end{abstract}

Keywords: Environmental Law, Garanhuns / PE, Nascent Yellow Pau. 


\section{INTRODUÇÃO}

A atual sociedade vem influenciando e sendo influenciada pelas ações que realizam diante dos recursos naturais disponíveis na superfície terrestre. Uma das grandes transformações diz respeito à constituição de áreas urbanas, articulada pelo homem em sua necessidade de ter um ambiente propício para a sobrevivência.

O homem provoca alterações intencionais sobre a superfície da Terra com o intuito de construir locais ou habitats para manutenção da vida e, simultaneamente, deve estar ciente que estas modificações trazem consequências na dinâmica dos ambientes. (DREW, 1986).

Para tanto, o ministério de meio ambiente, junto a seus diversos conselhos estabelecidos por lei, tem "princípios e estratégias para o conhecimento, proteção e recuperação do meio ambiente, o uso sustentável dos recursos naturais, a valorização dos serviços ambientais e a inserção do desenvolvimento sustentável [...]" (BRASIL, 2014a), e a instituição da Política Nacional do Meio Ambiente (BRASIL. LEI, $\mathrm{n}^{\circ} 6.938,1981$ ) com o objetivo de preservar, melhorar e recuperar a qualidade ambiental necessária à vida.

O Conselho Nacional do Meio Ambiente, Conama, é o órgão do qual o Sistema Nacional do Meio Ambiente, Sisnama, consulta e realiza deliberações, tendo como jurisdição estabelecer "normas e critérios" para o meio ambiente e recursos naturais: licenciamento ambiental, determinação da realização de estudos sobres os impactos ambientais de atividades e busca de alternativas extras, entre outros aspectos. (BRASIL, 2014b).

E ainda temos como aporte legislativo o Estatuto das cidades e Plano diretor municipal que determina para as cidades que possuem uma população superior a 20.000 habitantes, conforme Art. 41, inciso I da legislação (BRASIL. LEI, $\mathrm{n}^{\circ}$ 10.257), como sendo "o instrumento básico da política de desenvolvimento e expansão urbana".

E, por fim, porém não menos importante, temos o Código Florestal (BRASIL. LEI, 4.771.), ou melhor, o Novo Código Florestal (BRASIL. LEI, n²12.651.), que foi instituído recentemente tendo como objetivo o compromisso e a importância da proteção da vegetação nativa.

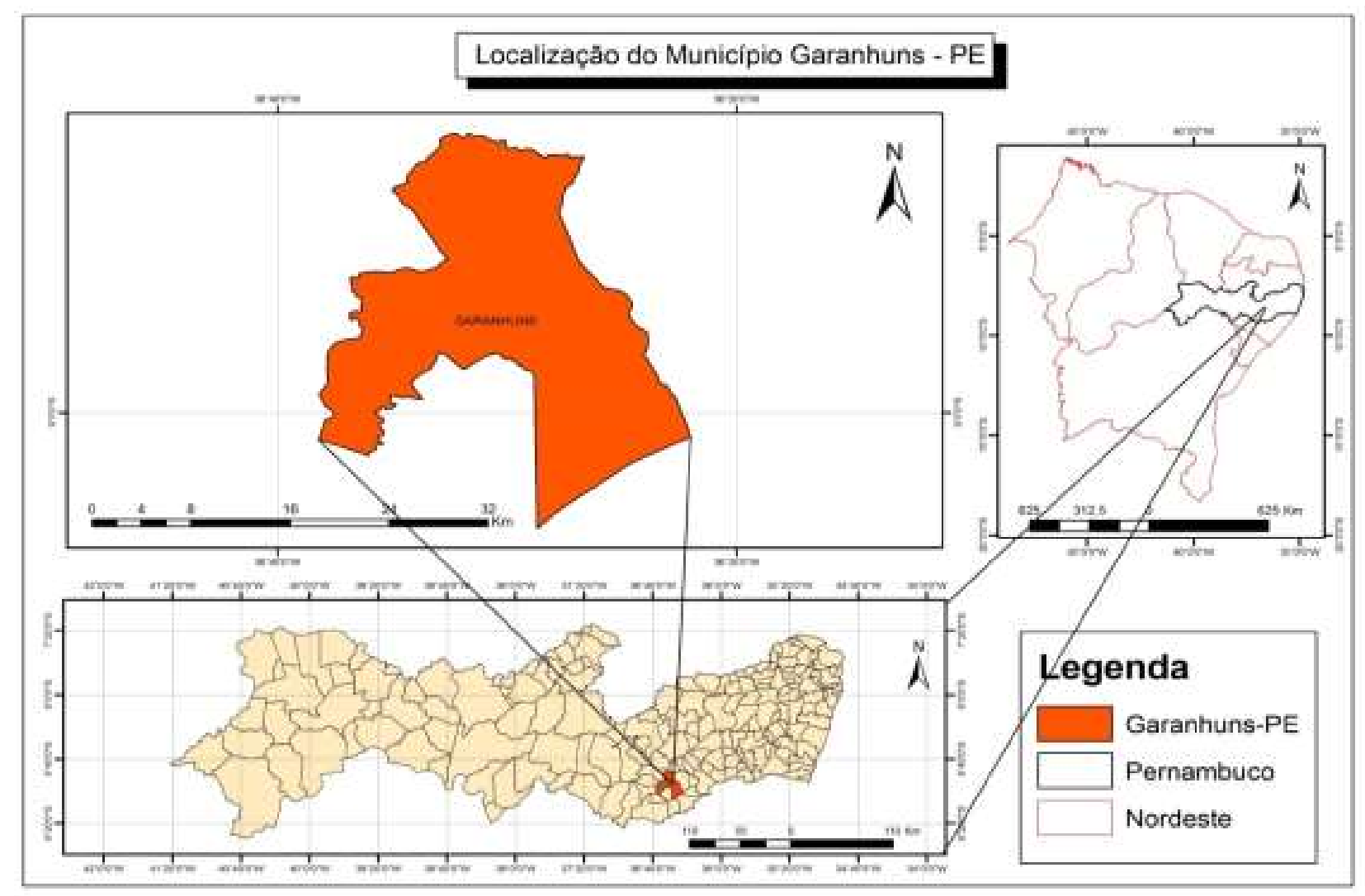

Figura 1: Mapa de localização politica-administrativa do município de Garanhuns.

Fonte: Adaptado pelos autores. 
São os principais instrumentos que servem como apoio a tomada de decisão quanto às ações que podem ser realizados no âmbito de planejamento e gestão ambiental, considerando que elas devem ter os seus desenvolvimentos e que isso acontece de forma sustentável e democrática.

Com isso, buscamos a atual legislação ambiental e, a partir de suas diretrizes, procuramos apontar suas determinações e indicar, sobre uma visão integrada, onde pode ser enquadrada a nascente de Pau amarelo, no município de Garanhuns-PE.

\section{I CaracterizaÇão da ÁREA de ESTUdo}

O munícipio de Garanhuns fica localizado na Microrregião Garanhuns do Estado de Pernambucano, numa altitude aproximada de 842 metros e coordenadas geográficas de $08^{\circ} 53^{\prime} 25^{\prime \prime}$ de latitude sul e $36^{\circ} 29^{\prime} 34^{\prime \prime}$ de longitude oeste (figura 1), a uma distância $228,8 \mathrm{~km}$ da capital Recife, cujo acesso é feito pela BR-101, e PE-126/177(CPRM, 2005).

Com uma população de 129.408 habitantes (IBGE, 2012), Garanhuns se destaca dos outros municípios da região por ser polo na disposição de serviços de saúde - com diversos hospitais, empresas de saúde - e educação - como UFRPE (Universidade Federal Rural de Pernambuco), UPE (Universidade de Pernambuco, Campus Garanhuns), a AESGA - Autarquia de Ensino Superior de Garanhuns, dentre outras e cursos técnicos no IFPE (Instituto Federal de Pernambuco) e outras.

Além disso, tem destaque no posicionamento geográfico do município que se encontra inserido, geologicamente, na Província Borborema. O relevo da unidade apresenta superfícies retrabalhadas, dissecado e vales profundos. Parte do agreste e da região litorânea de Pernambuco e Alagoas é formada pelo "mar de morros" que antecedem a Chapada da Borborema. (CPRM, 2005).

Temos como objetivo principal compreender e identificar como estão direcionadas as políticas públicas, em sua legislação, nos diversos níveis de escala aplicada, no local que abrange a nascente de Pau Amarelo.

\section{METODOLOGIA}

De inicio realizamos uma pesquisa bibliográfica, por meio digital, em endereços eletrônicos, através de livros, revistas, artigos acadêmicos, documentos e leis ambientais como base para se compreender as diretrizes que o Estado brasileiro dispõe.

De posse destas informações, começamos a pontuar artigos disponíveis nas leis, acima citadas, como forma para compreender e indicar, a partir das características constadas, uma área que apresenta condições de ser protegida, segundo o que a legislação ambiental esclarece.

$\mathrm{Na}$ segunda parte, confeccionamos mapas de localização da nascente de Pau Amarelo a partir de imagens do google earth, como também de arquivos shapefiles de vetores das diferentes escalas geográficas para localizar o município em estudo. Para tanto, foi necessário utilizar o software ARCGIS 9.3, pela sua capacidade de aquisição, tratamento e manipulação dos dados e de geração de informações espaciais.

Tivemos como base cartográfica os arquivos em anexo no plano diretor (GARANHUNS. LEI ${ }^{\circ}$ 3620) do mapeamento temático que faz parte do Plano diretor do município, sendo elas: Zoneamento Urbano - SEDE e Política Ambiental e Urbana - SEDE.

\section{RESULTADOS E DISCUSSÕES}

Além da legislação ambiental aqui mencionada, seria necessário ,como medida, que o poder público realizasse uma atualização e uma maior especificação das normas para a Política de Preservação, Recuperação e Conservação Urbana e Ambiental, esclarecendo a metodologia e os critérios adotados para promover intervenções objetivas, determinando um zoneamento ambiental que seja de forma integrada.

Que estas medidas possam ser adotadas para proteção da nascente e da massa arbórea, nativa ou exótica, com isolamento e fiscalização de interferências diretas ou indiretas que o homem possa vir a cometer, alterando qualidade e quantidade disponível dos recursos naturais. 
Podendo assim divulgar claramente a população, principalmente na área em estudo, da importância que aquele ambiente tem para manter a qualidade de vida e a disposição dos recursos ao homem. Mas também uma conscientização dos processos de influência antrópica podem acarretar uma intensa alteração ou, até mesmo, perda desse local.

A nascente se encontra localizada no município de Garanhuns-PE, se configura em um dos afluentes que abastecem a Bacia do Rio Mundaú, que é de domínio federal por ultrapassar os limites territoriais de um estado, ou seja, ela tem sua cabeceira no estado de Pernambuco e sua foz em Alagoas.

Está localizada no bairro Heliópolis, que apresenta uma divisão onde podemos observar, por imagens de satélite, através do google earth na internet (figura 2), o talvegue separa visualmente a topografia da área e a sociedade em sua diversas realações e movimentos. De um lado, Heliópolis, com toda sua estrutura urbana planejada e, de outro, Liberdade, numa ocupação oposta e apresentando uma população de baixo poder aquisitivo, segregados socialmente pelos serviços públicos. (SOARES; SANTOS; CAVALCANTI, 2013).

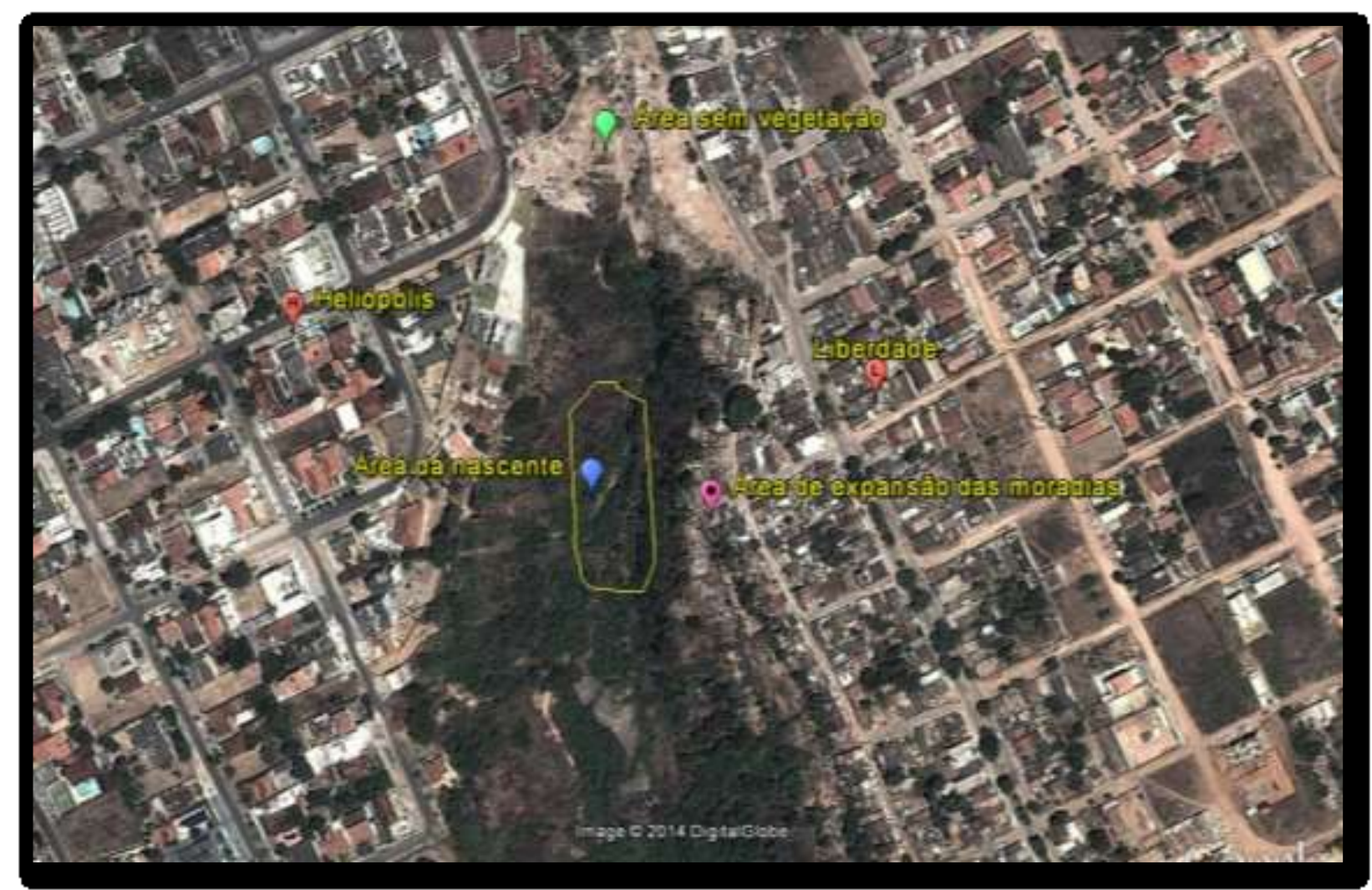

Figura 2: Imagem e caracterização da paisagem da área de localização da linha do talvegue. Fonte: Google Earth, adaptado pelos autores, 2014.

O processo de expansão urbana já está influenciando na paisagem da área em que se encontra a nascente em estudo, as moradias do lado da Liberdade estão de forma desornada da linha vertical para o talvegue. Isso pode acarretar, levando em consideração o compartimento de solo, o movimento de massa e, consequentemente, das edificações construídas.

A vegetação expressa função relevante:

A vegetação é um importante indicador geoambiental, pois sofre influencia dos fatores climáticos, edafológicos e bióticos. Exerce importante papel na estabilização dos geoambientes, visto que protegem o solo dos processos erosivos, facilita a distribuição, infiltração e acúmulo das águas pluviais e influencia nas condições climáticas do ambiente (p. 366). (ALMEIDA; CUNHA; NASCIMENTO, 2012) 
Além da capacidade de proteção - de recursos hídricos, do solo - que a vegetação exerce em torno e com os elementos que fazem parte da paisagem, executa um papel importante promovendo uma estabilidade - nos processos erosivos, ciclo hidrológico - na área.

A urbanização desenfreada tem influenciado para a realidade em que se encontra a nascente, nas proximidades do talvegue, efluentes das áreas pavimentadas são direcionados para o curso da nascente, a concentração de resíduos na vizinhança, são algumas das influencias antrópicas que foram observadas segundo Soares; Santos; Cavalcanti. (2013), acarretando, assim, dificuldades ambientais.

Conforme a respectiva lei do Novo Código Florestal (BRASIL. Lei ${ }^{\circ}{ }^{12}$. 651) de Maio de 2012, no Art. $3^{\circ}$, define-se uma área de APP da seguinte maneira:

II - Área de Preservação Permanente - APP: área protegida, coberta ou não por vegetação nativa, com a função ambiental de preservar os recursos hídricos, a paisagem, a estabilidade geológica e a biodiversidade, facilitar o fluxo gênico de fauna e flora, proteger o solo e assegurar o bem-estar das populações humanas.

Considerando essa Lei, no Art. $3^{\circ}$, inciso XVII ,abrange por nascente: "afloramento natural do lençol freático que apresenta perenidade e dá início a um curso d'água;". Assim está inserida a nascente de Pau Amarelo, que segue seu curso no Rio Pau Amarelo até o Mundaú

Segundo a lei do Novo Código florestal (BRASIL. Lei nº 12. 651), no capítulo que trata de áreas de preservação permanente, dispõe a seguinte determinação no Art. $4^{\circ}$ ao falar sobre uma Área de Preservação Permanente, em zonas rurais ou urbanas, para os efeitos desta Lei (tabela 1):

Tabela 1- Indicação da área de preservação permanente para largura de uma rio e do entorno de nascentes e olhos d’águas.

I - as faixas marginais de qualquer curso d'água natural perene e intermitente, excluídos os efêmeros, desde a borda da calha do leito regular, em largura mínima de:

Cursos d'água de menos de 10 (dez)
metros de largura.
IV - as áreas no entorno das nascentes e dos olhos d'água perenes, qualquer que seja
sua situação topográfica.
Nascentes e dos olhos d'água perenes.

As margens do rio que tenham 10 (dez) metros de largura necessitam de uma área de abrangência de 30 (trinta) metros para que se possam preservar as águas do rio, o solo e a biodiversidade. Para a nascente e olho d’água, um raio de 50 (cinquenta) metros de abrangência.

Atualmente a nascente em estudo, segundo o Art. 47 do Plano Diretor no quadro de parâmetros urbanístico, determina zonas ambientais que podem ser observadas nas figuras 3 e 4, que estão caracterizadas da seguinte maneira:

- ZBD - Zona de Baixa Densidade;

- SSS - Setor de Suporte e Sustentabilidade;

- SRA - Setor de Recuperação Ambiental;

- ZEIS - Zona Especial de Interesse Social;

- SMP - Setor de Manejo Provisório.

Para a caracterização da figura 4 , segundo o que consta na carta do plano diretor, a indicação (02) fala sobre a elaboração e a implementação do plano de manejo para recuperar o ambiente com o estabelecimento de normas e procedimentos para preservar e conservar as características morfológicas e de interesse hídrico, vegetal, paisagístico, entre outros. E mais específico à dinâmica do entorno da nascente estudada. 
Como isso, cumpre o que está colocado no Art. $6^{\circ}$, inciso II, alínea b 1 , sobre a necessidade de proteger os recursos hídricos das nascentes e corpos d'água e massa vegetal. O Art. $7^{\circ}$, alínea a, ressalta a proteção dos recursos naturais. O artigo Art. 11 expressa a criação de um Sistema Municipal de Unidades de Conservação - SMUC - para implementar programas que visam preservar, recuperar e conservar o ambiente natural. No inciso I, do mesmo artigo, na alínea b 1, que fala de unidades de conservação, classifica esta em uma Área de Proteção Ambiental e alínea II fala sobre a gestão de plano de recuperação e conservação das bacias do rio Mundaú e Canhoto (GARANHUNS. LEI. ${ }^{\circ}$ $3620,2008)$.
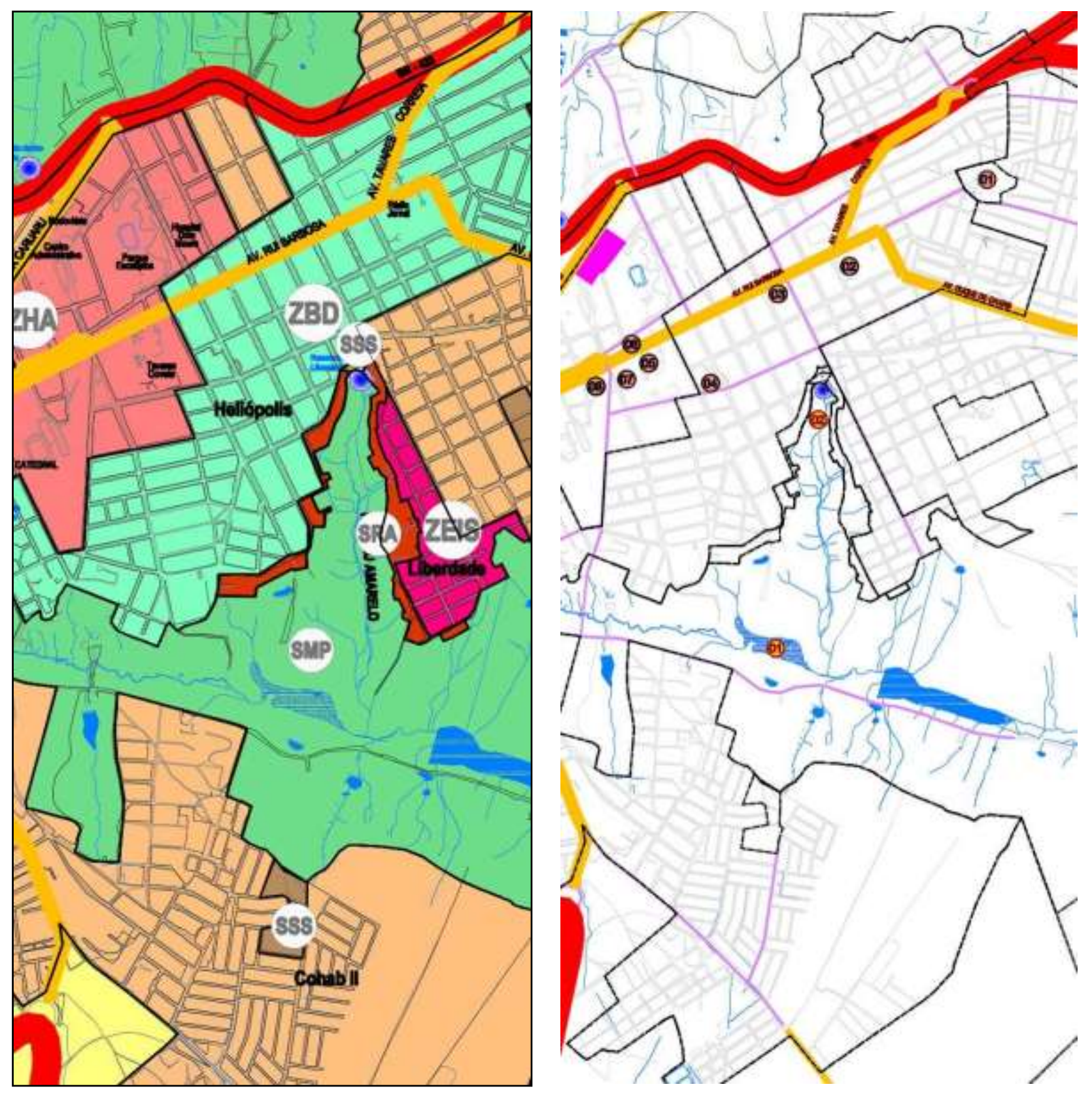

Figura 3 e 4: Zoneamento ambiental da área do talvegue e sistema vário e do talvegue Fonte: Adaptado do Plano Diretor do Município de Garanhuns-PE

Para tanto, não conseguimos identificar, através das cartas, uma área de proteção ambiental, mas a seguinte indicação: SSS - Setor de Suporte e Sustentabilidade e SRA - Setor de Rec. Ambiental, no local das proximidades da nascente pela figura 4 . 


\section{CONCLUSÃO}

A nascente de Pau Amarelo, como também todos os elementos componentes em sua área, pode sofrer grandes interferências no ambiente e, talvez, contaminação e assoreamento do Rio Pau Amarelo e do olho d'água, caso as medidas especificas de recuperação e conservação não forem adotadas.

A aplicação da legislação ambiental no município estudado poderia resultar na minimização das influências antrópicas e da própria interação dos elementos naturais - solo, vegetação, hídrico - de energia e matéria.

A recuperação, proteção e conservação do que trata a Lei Federal n ${ }^{\circ} 12.651$ e das ações de programas sustentáveis, dos quais dispõem o plano diretor do município para que a população e o próprio poder público possam fazer uso dos benefícios deste ambiente.

Esperamos que o poder público realize as normas de seus projetos, tendo como base a legislação ambiental pertinente. Pois deveriam determinar uma área de proteção ambiental ou, pelo Art. $4^{\circ}$, apresentado acima pela Lei Federal $n^{\circ} 12.651$, outorgar uma área de proteção permanente junto com os órgãos e cumprindo as leis necessárias. Mas que a princípio seja realizado um zoneamento ambiental da área em consideração, para se conseguir ter um diagnóstico da realidade em que se encontra o ambiente e quais são os tipos de influências que têm interferido na dinâmica e na conservação da nascente de Pau Amarelo.

\section{AGRADECIMENTOS}

A Universidade de Pernambuco - UPE/ Campus Garanhuns pelo apoio ao desenvolvimento do trabalho e minha formação acadêmica.

\section{REFERÊNCIAS}

ALMEIDA, N. V; CUNHA, S. B.; NASCIMENTO, F. R. A cobertura vegetal e sua importância na analise morfodinâmica da bacia hidrográfica do rio taperoá -nordeste do brasil/ paraíba. REVISTA GEONORTE, Edição Especial, V.3, n 4, p. 365-378, 2012.

BRASIL. Lei ${ }^{\circ} 10.257$, de 10 de julho de 2001. Diretrizes Gerais da Política Urbana e outras providências. Disponível em:<http://www.planalto.gov.br/ccivil_03/leis/leis_2001/110257.htm>. Acesso em: 17 jan. 2014. On-line.

BRASIL. Lei n ${ }^{\circ} 12.651$, de 25 de maio de 2012. BRASIL. Novo Código Florestal. Disponível em:< http:// www.planalto.gov.br/ccivil_03/_ato2011-2014/2012/lei/112651.htm>. Acesso em: 14 jan. 2014. On-line.

BRASIL. Ministério do Meio Ambiente. Lei, $\mathrm{n}^{\circ}$ 6.938, de 31 de agosto de 1981. BRASIL. Política Nacional do Meio Ambiente. Disponível em:<http://www.mma.gov.br/port/conama/legiabre.cfm?codlegi=313>. Acesso em: 17 jan. 2014. On-line.

BRASIL. Ministério do Meio Ambiente. Disponível em:<http://www.mma.gov.br/o-ministerio/apresentacao>. Acesso em: 21 fev. 2014a. On-line.

BRASIL. Ministério do Meio Ambiente. Disponível em:<http://www.mma.gov.br/port/conama/>. Acesso em: 23 jan. 2014b. On-line.

CPRM - Serviço Geológico do Brasil. Projeto cadastro de fontes de abastecimento por água subterrânea. Diagnóstico do município de Garanhuns, estado de Pernambuco. Recife: CPRM/PRODEEM, 2005.

DREW, D. Processos interativos homem-meio ambiente. São Paulo: DIFEL, 1986. 
GARANHUNS. Prefeitura Municipal. Lei n 3620, de 2008. Plano Diretor Participativo do Município de Garanhuns.

SOARES, A. B.; SANTOS, C. C. dos; CAVALCANTI, M. A. Problemática socioambiental urbana na nascente pau amarelo em Garanhuns-PE. Revista Brasileira de Geografia Física v.6, n.5, (2013) 1140-1157. Disponível em: < http://www.revista.ufpe.br/rbgfe/index.php/revista/article/viewFile/751/468 >. Acesso em: 17 mar. 2014. On-line. 